\title{
Surface Topography Quantification of Super Hard Abrasive Tools by Laser Scanning Microscopy
}

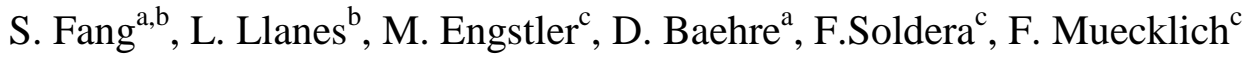 \\ a'Institute of Production Engineering, Saarland University, 66123 Saarbrücken, Germany \\ ${ }^{\mathrm{b}}$ CIEFMA - Dept. of Materials Science and Metallurgical Engineering, Universitat Politècnica de Catalunya, \\ Barcelona 08028, Spain \\ ${ }^{\mathrm{C} C}$ Chair of Functional Materials, Saarland University, 66123 Saarbrücken, Germany
}

\begin{abstract}
Non-conventional super hard abrasive tools are made of composite materials containing super hard grains, e.g., diamond or cubic boron nitride (CBN) grains, bound by a metallic constitutive phase. These tools are usually produced by means of sintering, and are widely applied in the abrasive machining processes of modern manufacturing, especially in precision machining. The abrasive grains, which induce the material removal processes, are embedded in the metallic binder. They emerge as a consequence of self-dressing, resulting in a self-sharping effect. Therefore, the cutting surface of the tool displays an irregular topography. Quantification of surface topography scenario may supply valuable information to evaluate and understand its correlation to wear mechanisms. In this study, an experimental protocol consisting of five steps: specimen preparation, surface scanning, image assembly, image digital processing and surface quantification, is proposed and validated by characterizing two CBN honing tools used for precision machining: B151/L2/10/50 (B151) and B91/128/x44/35 (B91) CBN honing stones. It involves the use of laser scanning microscopy and digital imaging processing for assessing significant dimensional, geometrical and positional properties of $\mathrm{CBN}$ grains at the surface of super hard abrasive tools. It is shown that surface topography quantification is an effective method to evaluate and obtain the defined parameters. However, smaller grains may require images with higher resolution; and thus, scanning must be refined. Finally, a critical comparative analysis of the experimental results attained for the studied tools points out honing stone B91 as more appropriated than B151 one for achieving a higher machining quality of the workpiece.
\end{abstract}

Keywords: Abrasive tools, CBN composite, Quantification, Laser Scanning Microscopy, Surface Topography.

\section{Introduction}

Non-conventional super hard materials are widely used in the tool fabrication industry, particularly for precision machining applications. They are composites consisting of two main components: abrasive ceramic grains and a metallic binder (Figure 1). Abrasive grains participate in the cutting processes due to their high hardness. Cubic form of the boron nitride, which is synthesized under high pressure and temperature, is commonly used as super hard abrasive [1,2]. In the material removal processes, the microstructure assemblage of the composite plays a significant role in the tool wear mechanism. It has been shown that lower CBN contents yields superior wear resistance in finish hard milling of tool steels $[3,4]$. On the other hand, direct correlation of hardness and fracture toughness to grain size and binder content has been studied and discussed by McKie and coworkers [5]. Surface topography can also have a relevant influence on the tool life. It is reported that smoothing of the tool surface topography can extend tool life during in high speed machining of Inconel 718 [6]. It is often observed that grains can degrade by cracking and break out during abrasive processes. Abrasive crystal types and shapes have strong influences on grain wear mechanism. For instance, micro-crystals split and produce sharp cutting edges, whereas mono-crystals lose their layers to generate sharp cutting edges in the machining processes. Grains are erupted when the micro-bonding force between grains and binder exceed some certain value. The bonding force can be influenced by the grain size, shape and orientation, etc. It has been noticed that the maximum bonding force can be achieved under optimal grain orientation [7]. Therefore, quantification of all the features associated with the ceramic grains becomes useful to understand the correlation between the microstructural assemblage and mechanical characteristics of the composite and the wear mechanisms of the tool material. 


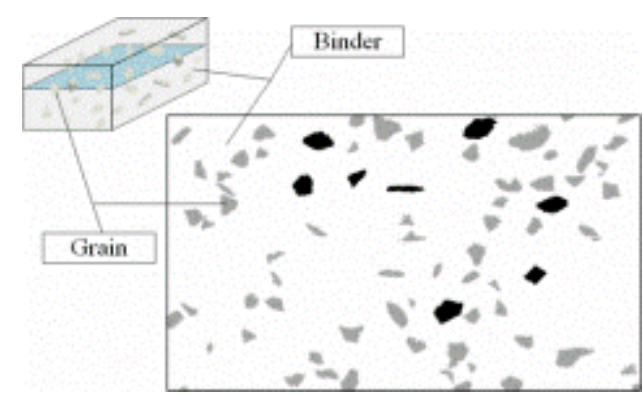

(a)

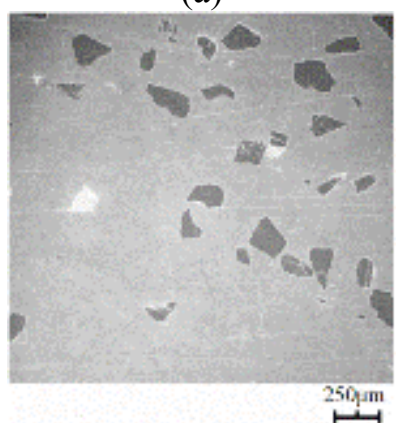

(c)

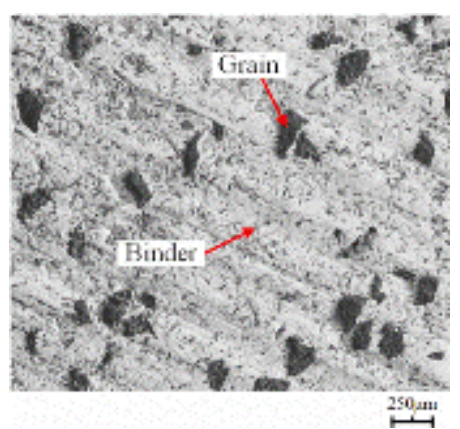

(b)

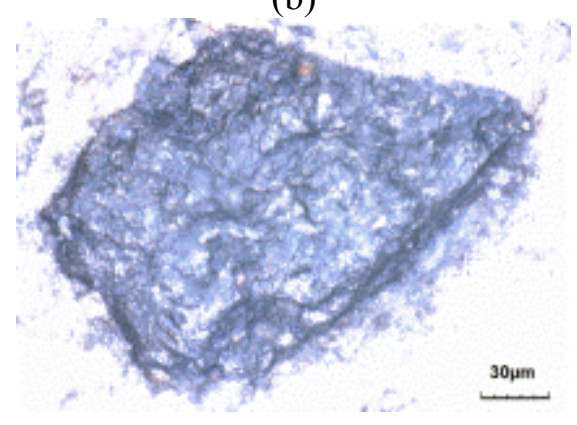

(d)

Figure 1. Microstructural assemblage of composite materials used to fabricate super hard abrasive tools: (a) schematic illustration and cross-section, (b) SEM image showing a typical surface aspect of a CBN honing tool; (c) SEM image of polished surface of B151 CBN honing tool; and (d) Laser scanning microscopy image of a single monocrystalline $\mathrm{CBN}$ grain

Nowadays, surface topography design of abrasive tools is becoming a frontier concept to improve the tool performance [8]. For instance, innovative manufacturing of honing stones has been approached by using glue and piezoelectric nozzle, as well as regular deposition with defined patterns of the ceramic grains on the tool surface [9]. Within this context, Kirsch and Aurich has recently proven that cooling efficiencies can be optimized using slotted grinding wheels [10]. Moreover, it has been reported that grinding wheels with defined grain patterns can ameliorate the grinding ability of materials, and reduce the forces and power in the grinding processes $[11,12]$. Hence, on the basis of surface topography design or modification, it seems clear that quantification of ceramic grain features can offer an effective and applicable path towards description and evaluation of new grain patterns to be generated on the tool surface.

Scanning electron microscopy (SEM) is a common characterization technique invoked for investigating the surface of cutting tools. Furthermore, the combined implementation of SEM with other techniques, such as focused ion beam (FIB), extends the application of the former into three-dimensional sectional analysis. For instance, different fracture mechanisms of mono- and micro-crystalline CBN grains have been discerned and compared using SEM [12]. Similarly, based on SEM inspection together with newly developed image processing techniques, quantitative characterization of microstructural changes associated with $\mathrm{Sr}$ modification and varying cooling rates during solidification of hypoeutectic Al-Si and Al-Si-Mg alloys have been achieved [13,14]. Although SEM is suitable for surface characterization, its application in practice is strongly limited by the implicit requirements regarding sample preparation and environment. Laser scanning microscopy (LSM) is also a technique commonly used not only for 2D metrological measurements, but also for 3D surface topography characterization. Compared with SEM, LSM implies lower costs, besides being simpler and easier to operate. LSM can meet most of the needs involved for surface topography investigation of the abrasive tools, especially for characterization of ceramic grain features. For example, a three-dimensional model of one single diamond grain has been reconstructed using LSM [15]. Moreover, topography characterization using laser methods has also been implemented as in-process inspection method in several abrasive machining processes [16]. The topography of grain protrusion of the truncated diamond grinding wheel has been visualized using laser methods, and some important parameters such as protrusion number, 
height etc. have been characterized [17]. However, implementation of laser methods to investigate ceramic grain parameters is rather limited to assessment of roughness of the tool surface and dimensional properties of single grains. Meanwhile, there is a lack of systematic and statistical investigations of other important parameters of the grains in abrasive tools, such as form, quantity and location.

Following the above ideas, it is main objective of this study to propose an experimental protocol aimed for systematically quantification of the ceramic grains on the tool surface, as well as for statistically assessment of the geometrical properties of grains on the cutting surface of abrasive tools.

\section{Materials and experimental aspects}

\subsection{CBN honing stones and laser scanning microscopy}

The specifications of honing stones offer basic information about the materials from what they are made, such as abrasive nature, grain size, crystal type, binder and grain concentration [18]. The abrasives are mostly corundum $\left(\mathrm{Al}_{2} \mathrm{O}_{3}\right)$, silicon carbide $(\mathrm{SiC})$, diamond $(\mathrm{C})$ and cubic boron nitride $(\mathrm{CBN})$ for the abrasive machining processes [19]. Abrasives should have high hardness and thermal stability. According to the Federation of the European Producers of Abrasives (FEPA) standard [20], which is used to identify the Diamond and CBN honing stones, grains are classified in terms of the mesh width in micrometres $(\mu \mathrm{m})$. The concentration is defined as the grain amount per one $\mathrm{cm}^{3}$ in the cutting layer [21]. For example, the specification (Table. 1) of the honing stone B151/L2/10/50 indicates that abrasive nature is cubic boron nitride (B), grain size is between $126 \mu \mathrm{m}$ and $150 \mu \mathrm{m}$ (151), crystal type and binder materials (L2 and 10 respectively), and a grain concentration of $12.5 \mathrm{Vol}-\%$ - i.e. about 0.44 $\mathrm{g} / \mathrm{cm}^{3}$ (50) [22]. The CBN grains have a mono-crystalline structure, which can form sharp cutting edges in the cutting processes due to self-generating nature (Figure 1 (d)). A $\mathrm{Cu} / \mathrm{Sn} / \mathrm{Co} / \mathrm{Ag}$ alloy is used as the binder.

Table 1. Properties of the honing stones B151/L2/10/50 and B91/128/x44/35

\begin{tabular}{llllll}
\hline Honing Stone & $\begin{array}{l}\text { Mean grain } \\
\text { size }(\mu \mathrm{m})\end{array}$ & $\begin{array}{l}\text { Max. grain } \\
\text { size }(\mu \mathrm{m})\end{array}$ & $\begin{array}{l}\text { Min. grain size } \\
(\mu \mathrm{m})\end{array}$ & $\begin{array}{l}\text { Grain concen- } \\
\text { tration }(\text { Vol- } \%)\end{array}$ & $\begin{array}{l}\text { Den- } \\
\text { sity }\left(\mathrm{g} / \mathrm{cm}^{3}\right)\end{array}$ \\
\hline B151 & 138 & 150 & 126 & 12.5 & 0.44 \\
B91 & 83 & 90 & 76 & 8.75 & 0.31 \\
\hline
\end{tabular}

The LSM Olympus Lext OLS3100 is used to acquire the images of the honing stone surfaces. The LD laser with the wavelength of $408 \mathrm{~nm}$ is employed as illumination resource. It includes a $150 \mathrm{~mm} \times 100$ $\mathrm{mm}$ auto-stage, equipped with the maximum vertical movement of $70 \mathrm{~mm}$ which is able to support the specimen with maximum height of $100 \mathrm{~mm}$. The objective lenses vary from $5 \mathrm{x}$ to 100x, with the optical zoom from $1 \mathrm{x}$ to $6 \mathrm{x}$. The LSM allows for a resolution of $0.01 \mu \mathrm{m}$.

\subsection{Assessment parameters}

Based on the surface topography quantification, important geometrical properties (Figure 2) of single CBN grains as well as the statistics are measured and analyzed in terms of quantity, dimension, form and position. 


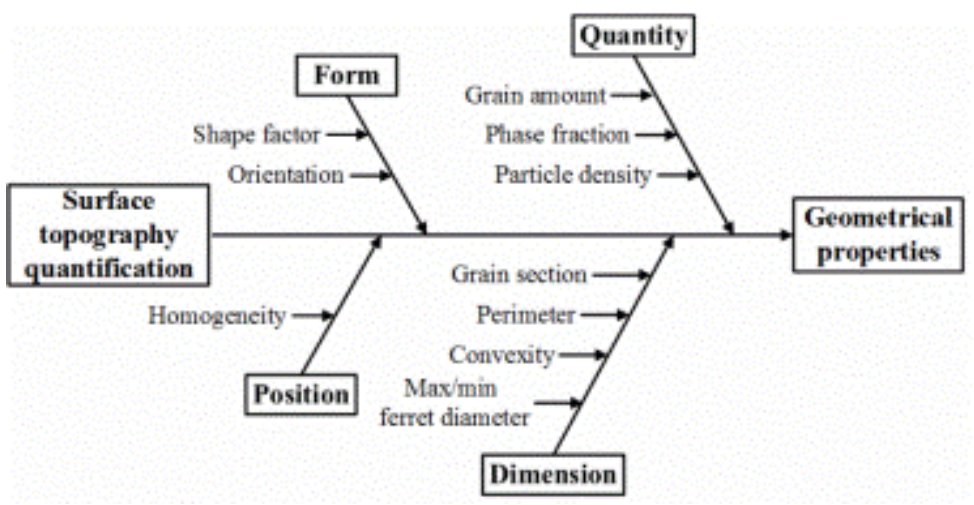

Figure 2. Assessment parameters concerning surface topography quantification

\subsubsection{Quantitative parameters}

Three parameters (Table 2) have been used to describe the quantitative properties of the grains: grain amount $N_{t}$, phase fraction $r_{p}$ and particle density $D$. Phase fraction $r_{p}$ is calculated by Equation (1):

$r_{p}=\frac{s_{1}}{S_{2}}$

$S_{i}$ : total grain sections

$S_{\text {s: }}$ surface area

Particle density $D$ is calculated by Equation (2):

$D=\frac{N_{t}}{S_{s}}$

$N_{t}$ : Grain amount

Table 2. Quantitative parameters

\begin{tabular}{ll}
\hline Parameters & Definition \\
\hline Grain amount $N_{t}$ & number of all the observed grains on the analyzed surface \\
Phase fraction $r_{p}$ & ratio of the total grain section $\left(S_{t}\right)$ to the surface area $\left(S_{s}\right)$ \\
Particle density $D$ & grain amount per $\mathrm{mm}^{2}$ \\
\hline
\end{tabular}

\subsubsection{Dimensional parameters}

Six parameters (Table 3 and Figure 3) are invoked to indicate the dimensional parameters of the grains: Grain section $S g$, Perimeter $U$, Convex perimeter $V$, Convexity $K$ and Max/min Feret diameter $F_{\text {max }} / F_{\text {mix }}$.

Convexity $[23,24]$ is given by Equation (3):

$$
K=\left[\frac{V}{v}\right]^{2}
$$

$K$ : Convexity

$V$ : Convex particle perimeter

$U$ : Particle perimeter

Table 3. Dimensional parameters

\begin{tabular}{ll}
\hline Parameters & Definition \\
\hline Grain section $S g$ & grain cross-section area \\
Perimeter $U$ & grain contour length \\
Convex perimeter $V$ & contour length of the convex grain \\
\hline
\end{tabular}




\begin{tabular}{ll}
\hline Convexity $K$ & $\begin{array}{l}\text { quadratic value of the ratio of the perimeter to the convex perimeter of } \\
\text { the particle } \\
\text { maximal/minimal distance between two parallel tangents of the particle }\end{array}$ \\
Max/min Feret diameter & at an arbitrary angle \\
$F_{\max } / F_{\min }$ &
\end{tabular}

Convex particle perimeter is always inferior or equal to the real perimeter of the particle; therefore, the convexity value should lie between 0 and 1 . Convexity describes the deviation grade of the particle perimeter from its convex perimeter. Convex perimeter of a particle is less sensitive when the shape profile becomes less smooth, which can result from the change of the size and number of the irregularities on the border [25]. Feret diameter measures the perpendicular distance between parallel tangents touching opposite sides of the profile. This parameter is commonly used to measure and describe a randomly oriented particle [26,27].

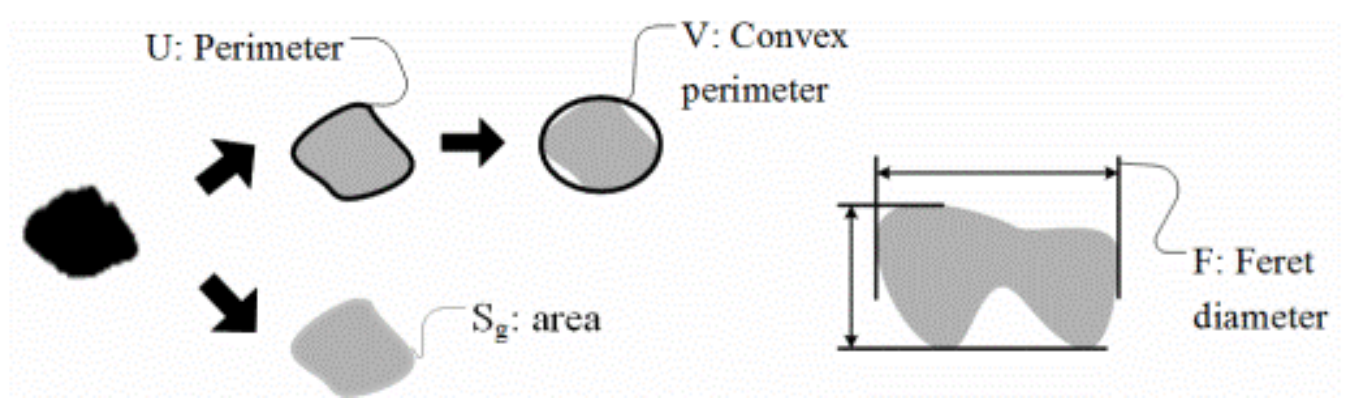

Figure 3. Schematic illustration of dimensional perimeters

\subsubsection{Form parameters}

Two parameters (Table 4) have been used to describe form-related features of the grains: shape factor $f$ and grain orientation. Grain shape is assessed and quantified by Equation (4) [28]:

$f=4 \pi \frac{s_{g}}{V^{2}}$

$f:$ Shape factor

$S_{g}$ : Grain section

$V$ : Convex particle perimeter

Table 4. Form parameters

\begin{tabular}{ll}
\hline Parameters & Definition \\
\hline $\begin{array}{l}\text { Shape factor } f \\
\text { Orientation }\end{array}$ & $\begin{array}{l}\text { circularity grade } \\
\text { angle } \theta \text { between the } \mathrm{X} \text {-axis and the long axis of the adjusted ellipse of the particle }\end{array}$ \\
\hline
\end{tabular}

Shape factor is a dimensionless quantity used in image analysis and microscopy that numerically describe the particle shape, independent of its size $[29,30]$. According to the definition, the value of the Shape factor $f$ lies between 0 and 1 . The indicator allows for the quantification of the shape in terms of the area and corresponding perimeters. Table 5 lists the evolution of the shape factor as a function of the shape side numbers. For an ideal circle, the factor value is 1 . The factor gets lower when the number of the shape side decreases as well as the shape stretches. The factor tends to 0 when the particle is stretched or elongated.

Table 5. Shape factor as a function of the corresponding geometries 


\begin{tabular}{|c|c|c|c|c|c|c|c|c|}
\hline & Circular & Hexagon & Pentagon & Ellipse & Squar & Rectangle & Triangle & Elongated \\
\hline Shape & & & & & & & & \\
\hline $\begin{array}{l}\text { Shape } \\
\text { factor }\end{array}$ & 1 & 0.907 & 0.865 & $0.8^{*}$ & 0.785 & $0.698^{*}$ & 0.604 & $<0.5$ \\
\hline
\end{tabular}

*: $a: b=2: 1$, a:long side, b: short side

Grain orientation is illustrated in Figure 4.

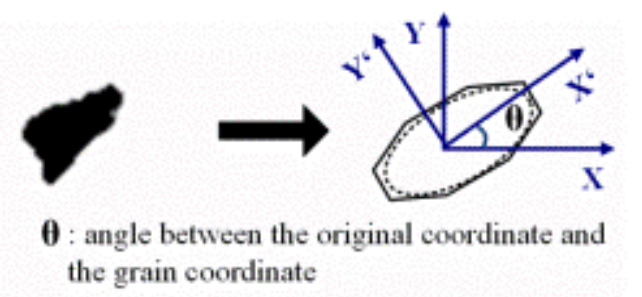

Figure 4. Schematic illustration of grain orientation

\subsubsection{Positional parameter}

Abrasive grains have random distributions on the surface, relative to its quantity and position. In this study, it aims to describe the grain distribution from a quantified point of view, instead of from a statistical analysis one [31]. Thus, homogeneity (Table 6) is selected to describe the grain distribution on the surface. Figure 5 gives an example of homogeneity in terms of phase amount: there is equal number of grains on the surfaces (1), (2), (3), but grain distribution on each of them is different; therefore, they exhibit distinct homogeneities.

(1)

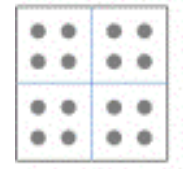

$\mathrm{H}_{(1)}$
(2)

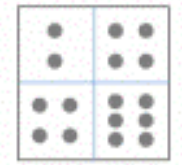

$\mathrm{H}_{(2)}$
(3)

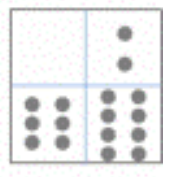

$\mathrm{H}_{(3)}$

Figure 5. Schematic illustration of homogeneity (e.g., object number)

Table 6. Positional parameters

\begin{tabular}{lll}
\hline Parameters & Definition & Equation \\
\hline Homogeneity $(\mathrm{H})$ & $\begin{array}{l}\text { similarity of its components considering a given } \\
\text { attribute }\end{array}$ & $H_{(\mathrm{y})=\sum_{\mathrm{i}=1}^{\mathrm{n}}\left(F_{(\mathbb{i})}-F_{(\mathrm{i}-1)}\right)\left(L_{(\mathrm{i})}-L_{(\mathbb{i}-1)}\right)}$ \\
\hline
\end{tabular}

Homogeneity $H_{(y)}$ can be interpreted by the Gini index: $H_{(y)}=1-G_{(y:} G_{(y:}$ is the Gini index, proposed to describe the mean difference from all observed quantities [32]. Therefore, homogeneity of a system is defined as the similarity of its components considering a given attribute [33]. Equation (5) gives the mathematic definition of homogeneity. Quantification assessment of microstructural homogeneity can be achieved by means of the Lorenz curve [6]. Homogeneity $(\mathrm{H})$ is given by the ratio between the area (AL) below the Lorenz curve and the area (AE) below the line of equality [34]. Therefore, the value of the homogeneity $\mathrm{H}$ is between 0 and 1 . The higher is the value $\mathrm{H}$, the more homogenous is the system.

$$
H_{(y)}=\sum_{i=1}^{n}\left(F_{(\mathbb{D})}-F_{(i-1)}\right)\left(L_{(\mathbb{i})}-L_{(i[-1)} ;\right.
$$


$F_{(\mathbb{0})}$ : cumulative share of components of the system

$L_{\text {Yif: }}$ : cumulative share of the values of the attribute

In order to describe the microstructural homogeneity in $2 \mathrm{D}$ analysis, region homogeneity $\left(h_{k}\right)$ is chosen as an indicator. $h_{F}$ is defined as the product (Equation 6) of the two one-attribute-based homogeneities: homogeneity of object number $H_{\text {(object number] }}$ and homogeneity of phase amount $H_{\text {(Phase amount: }}$

$h_{R}=H_{(\text {object number) }} H_{\text {(phase amount) }}$

The entire surface is equally divided into 10 sections. In each section, the object number and the phase amount are counted, and then the two one-attribute-based homogeneities, $H_{\text {(object number] }}$ and $H_{\text {(phase amount; }}$, can be obtained by Equation (5), respectively.

\subsection{Experimental procedure}

The experimental procedure consists of the following steps: specimen preparation, surface scanning, image assembly, image digital processing and surface quantification. Compared with the conventional microscopy, LSM has strong advantages in the 3D investigation of the surface. Reduction of the background influence of the confocal plane as well as the image processing capacity of the LSM allow for obtaining high quality images [35]. It is also suitable to segment the grains from the binder [15]. By using the software Imagic Image Access, the image series are assembled. With the software a4i, the assembled image can be binarized, and then quantified.

\subsubsection{Specimen preparation}

The specimens of the honing stones B151 and B91 have a dimensions of $20 \times 4.95 \times 3 \mathrm{~mm}$, and the investigated surfaces have been fine polished. A gold film has been deposed on the surface to improve the image contrast. The polishing procedure is detailed in Table 7. Polished B151 surface is shown in Figure 1(c).

Table 7. Specimen preparation procedure

\begin{tabular}{lllll}
\hline Procedure & $\begin{array}{l}\text { Pre- } \\
\text { grinding }\end{array}$ & Fine grinding & Pre-polishing & Fine Polishing \\
\hline Lubrication & Water & $\begin{array}{l}6 \mu \mathrm{m} \text { Diamond Sus- } \\
\text { pension }\end{array}$ & $\begin{array}{l}3 \mu \mathrm{m} \text { Diamond Sus- } \\
\text { pension }\end{array}$ & $\begin{array}{l}1 \mu \mathrm{m} \text { Diamond Sus- } \\
\text { pension }\end{array}$ \\
$\begin{array}{l}\text { Force per Speci- } \\
\text { men }(\mathrm{N})\end{array}$ & 20 & 15 & 15 & 15 \\
$\begin{array}{l}\text { Time (min) } \\
\begin{array}{l}\text { Platen rotation } \\
(\mathrm{r} / \mathrm{min})\end{array}\end{array}$ & 7 & 5 & 3 & 3 \\
\hline
\end{tabular}

\subsubsection{Surface scanning and image assembly}

The size of the image recorded by the LSM is limited by the objective lens. Therefore, the surface is sectioned, scanned and assembled to obtain an image of the entire surface with high resolution. Each section is measured and numerated under identical conditions. Figure 6 shows the surface sectioning and assembly processing. The LSM unit is set to measure the surface with the objective $5 \mathrm{x}$ (numerical aperture: 0.15 , optical correction: MPlanFL N), which allows for the measuring area $1920 \times 2560 \mathrm{\mu m}^{2}$ with the resolution of 1024 pixels $\times 786$ pixels. According to the surface dimension, the surface is sectioned into 18 parts, which are assembled in the next step to obtain an image of the entire surface. 


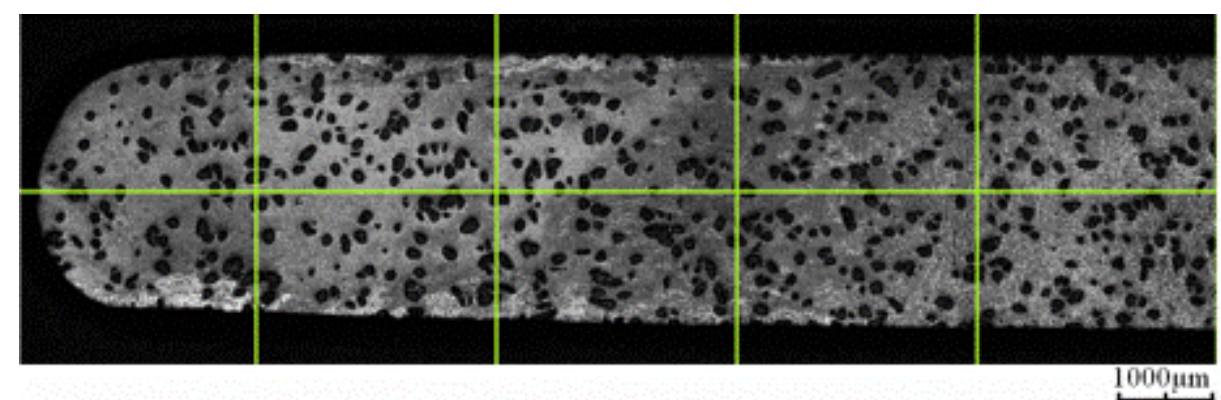

Figure 6. Example of surface sectioning and assembly by LSM

\subsubsection{Image digital processing and surface quantification}

Grain quantification is based on the segmentation of acquired images and subsequent image processing. Segmentation aims to extract the grains from the binder. Meanwhile, it eliminates the influence of the binder and some defects induced during the metallographic preparation, such as scratches, grain split, etc. Figure 7(a) shows an acquired image of the specimen B151 by LSM, where two major phases can be clearly identified: CBN grains and binder, according to the different contrast. Figure 7(b) shows the image after the segmentation, where highlighted green blocks represent the grains corresponding with the grey blocks in Figure 7(a).

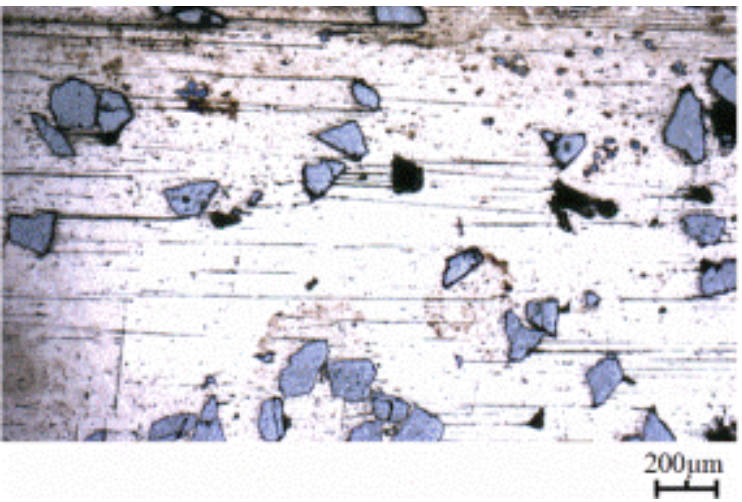

(a)

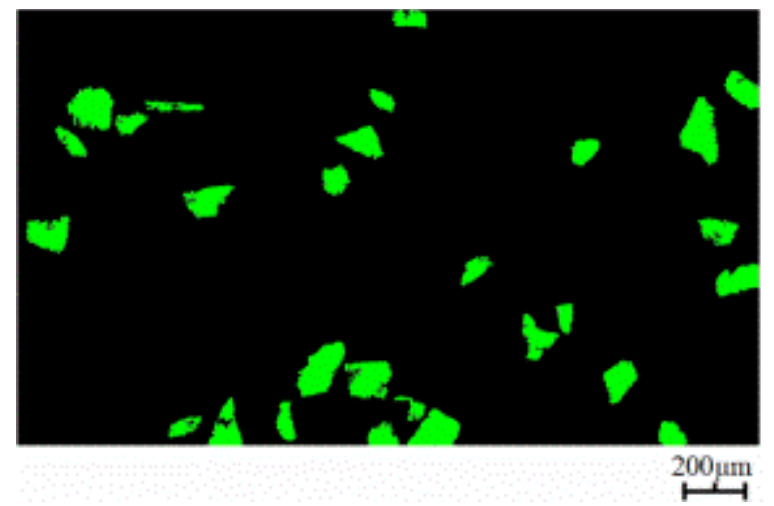

(b)

Figure 7. LSM images of B151 surface: (a) before segmentation, (b) after segmentation

However, the accuracy of the segmentation is strongly influenced by the quality of the acquired images. Possible defaults of the segmented images can be induced from the equipment accuracy or from the specimen preparation. For example, Figure 8(a) shows an image processing case for a micrograph without defaults. Figure 8(b) is an example of a grain with a pore in the center which is produced in the metallographic processing due to the grain rough edges and its fragility. Figure 8(c) shows the usual accuracy defaults which emerge when two grains are situated too close to each other. The two grains are treated by the software as one large grain. However, these artifacts may be reduced by morphological treatments such as erosion and dilation in the image digital processing. Small pores inside particles can be filled by a dilation process where one row of pixels is added to every boundary of the grains. Small bridges between particles can be removed by erosion, where one row of pixels is removed from each grain. When the grain is found on the specimen border, the software counts the grain number as 0.5 for the statistics. Grain quantification is executed following the correction of the segmented image.

$$
\text { Acquisition Segmentation Correction }
$$


(a)
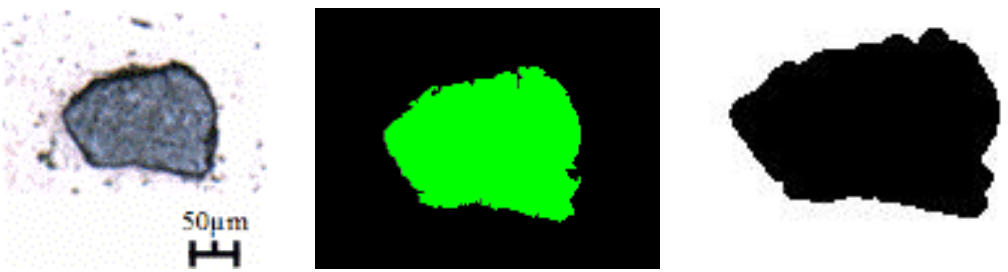

(b)

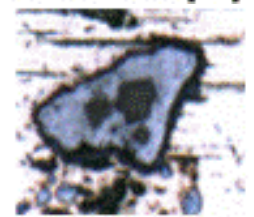

$50 \mu \mathrm{m}$
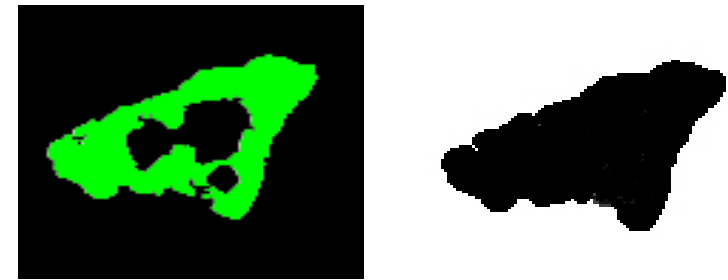

(c)
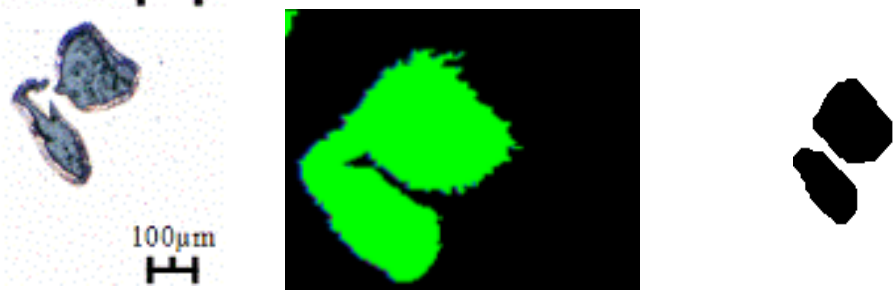

Figure 8. Common errors and reparation in the image processing: (a) no default,

(b) pore, (c) adhesion

\section{Results and discussion}

Figure 9 shows the surfaces of the honing stones B151 and B91 after the image processing. The results of quantification are presented in the following sections.

(a)

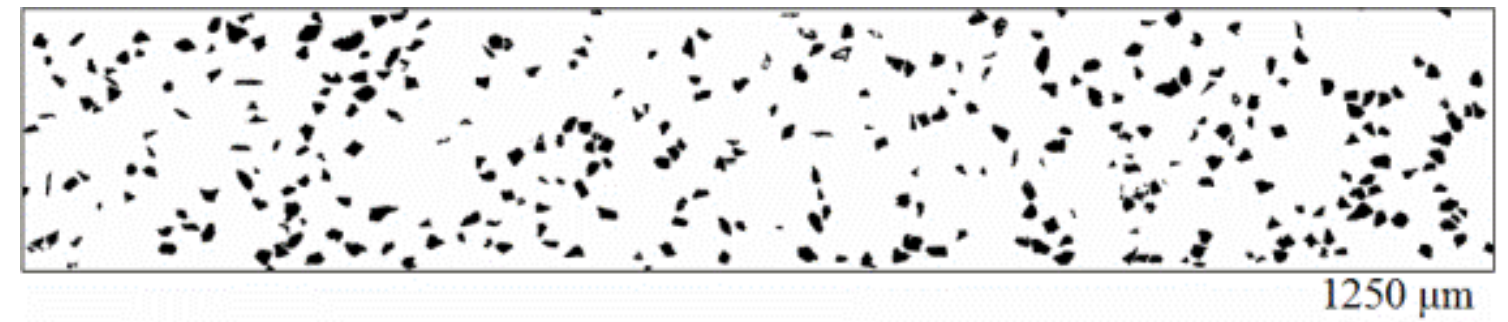

(b)

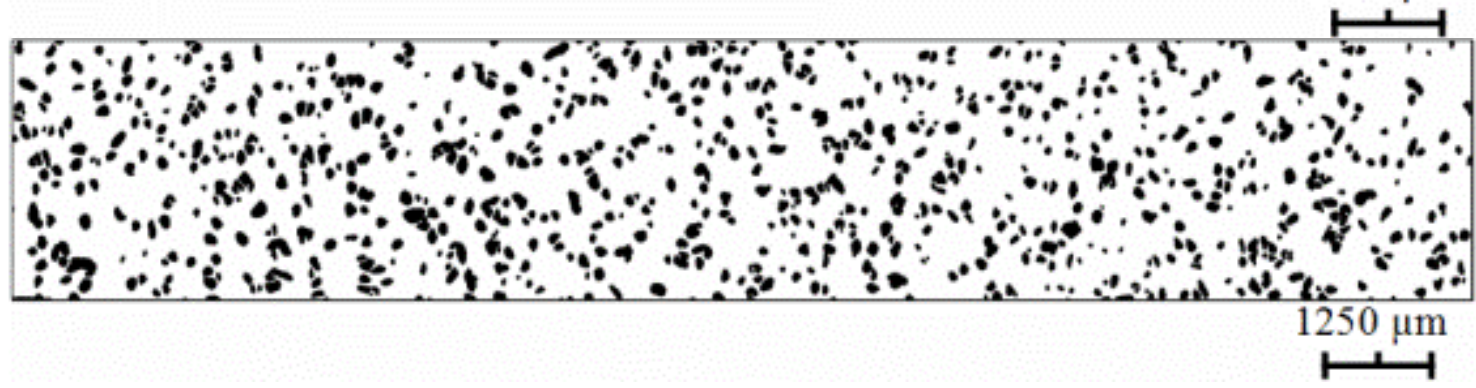

Figure 9. B151 (a) and B91 (b) grain distribution after image digital processing

\subsection{Quantitative parameters}

Results of grain quantity are displayed in Table 8 . On the working surface of the honing stone B151, a total of 355 grains with an area $S_{t}$ of $3.75 \times 10^{6} \mu m^{2}$ have been analyzed. The scanned surface $S_{s}$ is $4.22 \times 10^{7} \mu m^{2}$. Thus, the phase fraction $r_{p}$ and particle density $D$ of CBN grains is $8.89 \%$ and 8.4 $\mathrm{mm}^{-2}$, respectively. For the honing stone B91, 743 grains with an area $S_{t}$ of $7.39 \times 10^{6} \mu \mathrm{m}^{2}$ have been identified on the scanned surface $S_{s}$, i.e. $4.44 \times 10^{7} \mu m^{2}$. Thus, the specimen has a phase fraction $r_{p}$ of $16.63 \%$ and a particle density $D$ of $16.7 \mathrm{~mm}^{-2}$. 
Table 8. Surface grain quantity of the honing stones

\begin{tabular}{llllll}
\hline $\begin{array}{l}\text { Honing } \\
\text { Stone }\end{array}$ & $\begin{array}{l}\text { Grain Quan- } \\
\text { tity } \boldsymbol{N}_{\boldsymbol{t}}\end{array}$ & $\begin{array}{l}\text { Surface Area } \boldsymbol{S}_{s} \\
\left(\mu \mathrm{m}^{2}\right)\end{array}$ & $\begin{array}{l}\text { Total Grain Sec- } \\
\text { tions } \boldsymbol{S}_{\boldsymbol{t}}\left(\mu \mathrm{m}^{2}\right)\end{array}$ & $\begin{array}{l}\text { Phase Frac- } \\
\text { tion } \boldsymbol{r}_{p}\end{array}$ & $\begin{array}{l}\text { Particle Density } \\
D\left(\mathrm{~mm}^{-2}\right)\end{array}$ \\
\hline B151 & 355 & $4.22 \times 10^{7}$ & $3.75 \times 10^{6}$ & $8.89 \%$ & 8.4 \\
B91 & 743 & $4.44 \times 10^{7}$ & $7.39 \times 10^{6}$ & $16.63 \%$ & 16.7 \\
\hline
\end{tabular}

\subsection{Dimensional parameters}

Table 9 lists the mean values of the dimensional parameters obtained from the grain quantification. The grains on the surface of the honing stone B151 have mean section $S_{g}$ of $10.6 \times 10^{3} \mu \mathrm{m}^{2}$ and mean convex perimeter $V$ of $391.0 \mu \mathrm{m}$. The median value of ferret diameters $F$ is $122.8 \mu \mathrm{m}$, which is slightly inferior to the mean grain size $138 \mu \mathrm{m}$ (Table 1). Assuming that grains had a spherical profile; a section $S_{g}$ of $14.9 \times 10^{3} \mu^{2}$ and a perimeter $V$ of $433.3 \mu \mathrm{m}$ are assessed for individual particles. The grains on the surface of the honing stone B91 have mean section $S_{g}$ of $9.9 \times 10^{3} \mu \mathrm{m}^{2}$ and mean convex perimeter $V$ of $360.5 \mu \mathrm{m}$. The median value of ferret diameters $F$ is $114.4 \mu \mathrm{m}$, which is larger than the mean grain size $83 \mu \mathrm{m}$ (Table 1). It can also be assumed that grains have a spherical profile; therefore, a section $S_{g}$ of $5.4 \times 10^{3} \mu \mathrm{m}^{2}$ and a perimeter $V$ of $260.8 \mu \mathrm{m}$ may be estimated for the individual particles. The average convex perimeter of B91 as well as the average cross section is superior to the theoretical mean values.

Table 9. Mean values of the dimensional parameters

\begin{tabular}{|c|c|c|c|c|c|}
\hline $\begin{array}{l}\text { Honing } \\
\text { Stone }\end{array}$ & $\begin{array}{l}\text { Grain section } S_{g} \\
\left(\mu m^{2}\right)\end{array}$ & $\begin{array}{l}\text { Convex Perimeter } \\
V(\mu \mathrm{m})\end{array}$ & $\begin{array}{l}\text { Convexity } \\
K\end{array}$ & $\begin{array}{l}\text { Max Feret diameter } \\
F_{\max }(\mu \mathrm{m})\end{array}$ & $\begin{array}{l}\text { Min Feret diameter } \\
F_{\text {min }}(\mu \mathrm{m})\end{array}$ \\
\hline$\overline{\mathrm{B} 151}$ & $10.6 \times 10^{3}$ & 391.0 & 0.89 & 94.1 & 151.2 \\
\hline B91 & $9.9 \times 10^{3}$ & 360.5 & 0.96 & 91.3 & 137.7 \\
\hline
\end{tabular}

According to histograms, $80 \%$ of the grains have a section evenly situated near the mean value (Figure 10). Figure 11 shows the convexity histograms of the honing stones B151 and B91. For the honing stone B151, most of the grains have a convexity between 0.75 and 0.95 , whereas for the honing stone B91, it lies between 0.95 and 1 . In terms of the convex perimeters (Figure 12) and the ferret diameters (Figure 13), the grains exhibit approximate normal distributions.

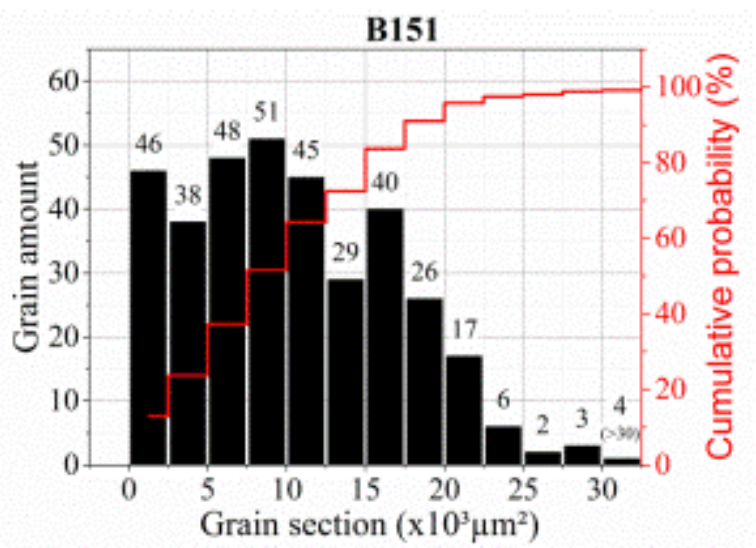

(a)

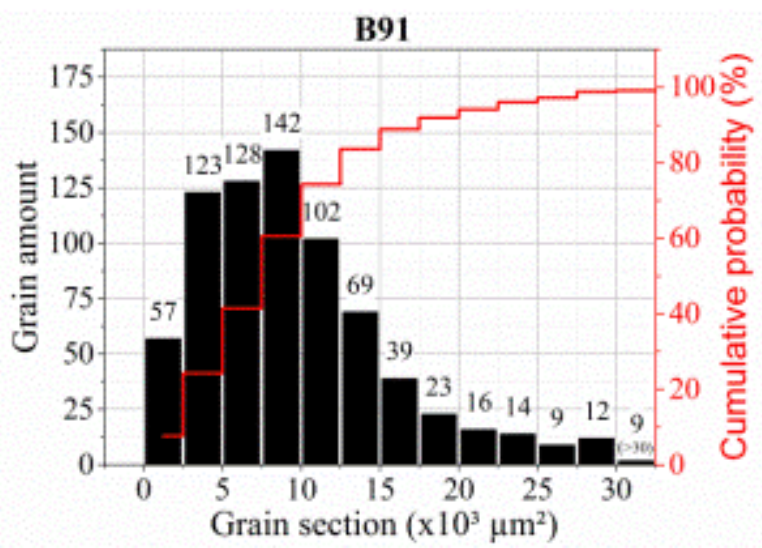

(b)

Figure 10. Grain sections of B151 (a) and B91 (b) 


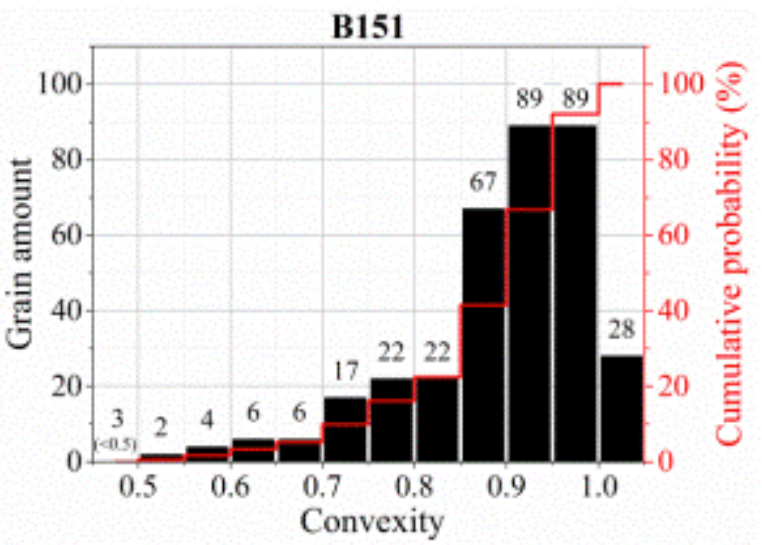

(a)

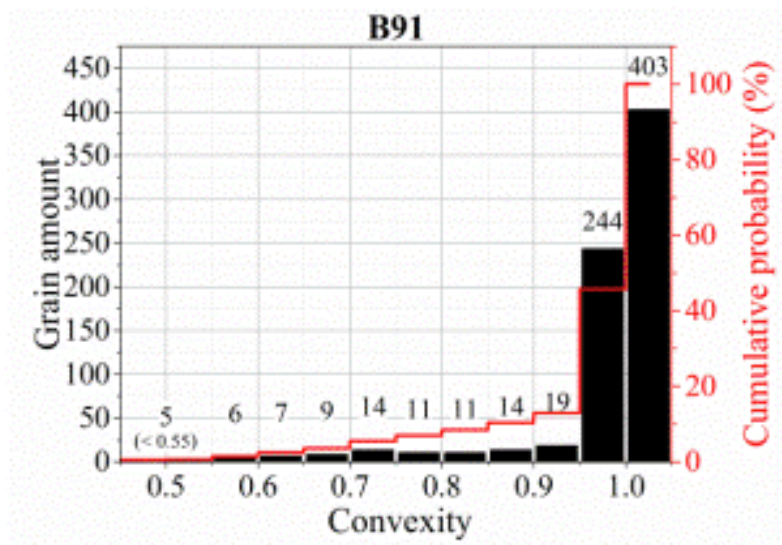

(b)

Figure 11. Grain convexity of B151 (a) and B91 (b)

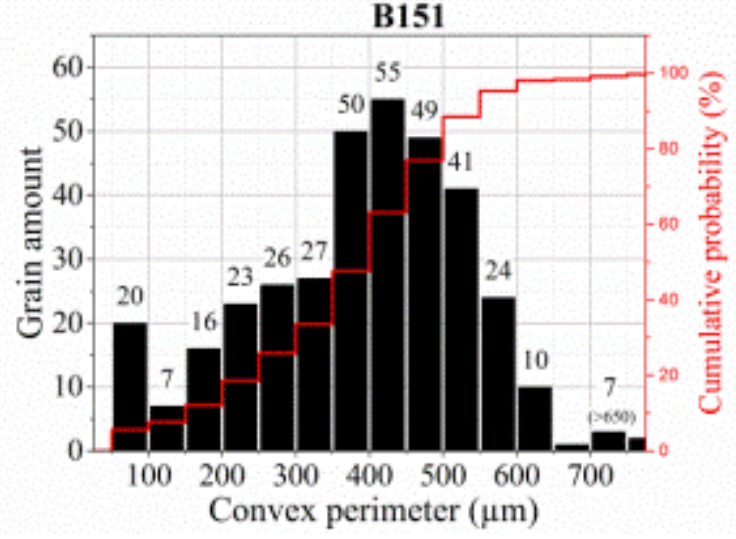

(a)

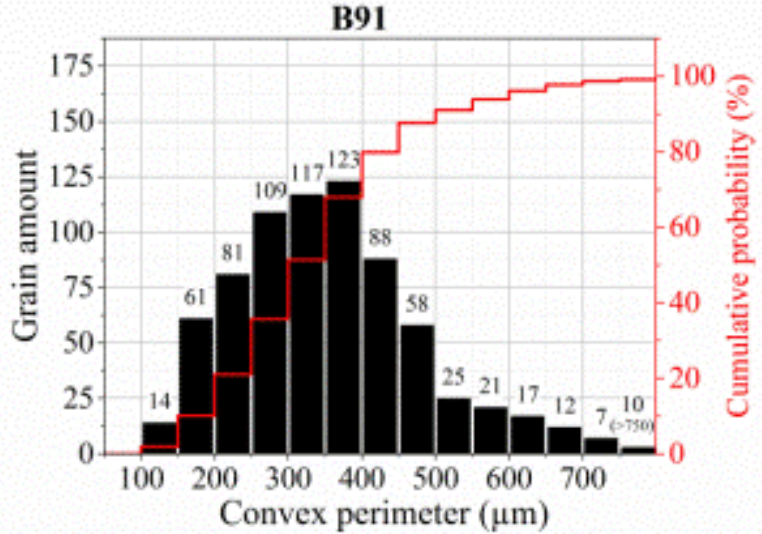

(b)

Figure 12. Grain convex perimeter of B151 (a) and B91 (b)

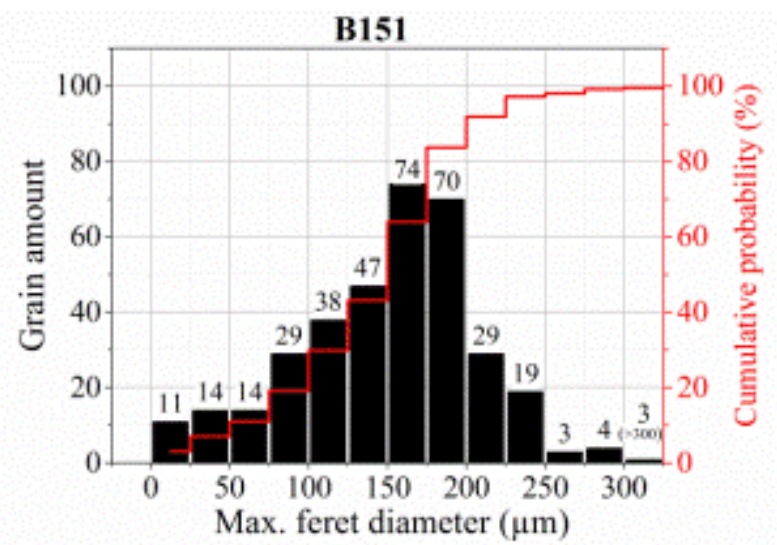

(a)

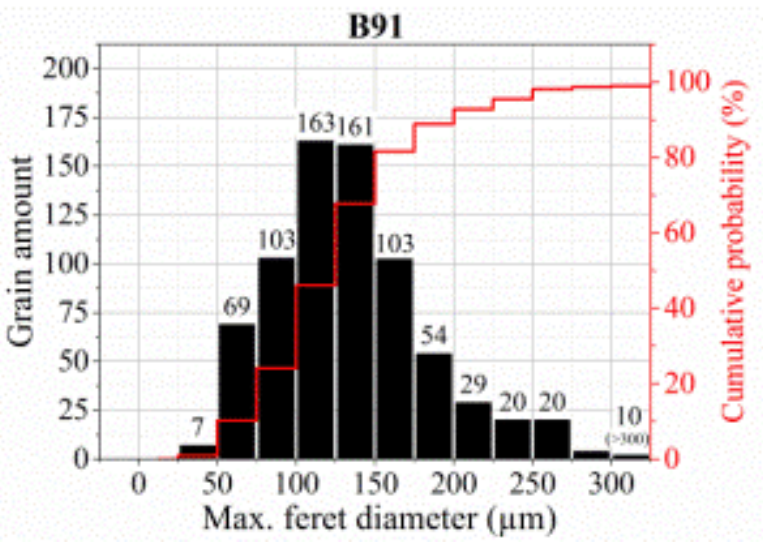

(b) 


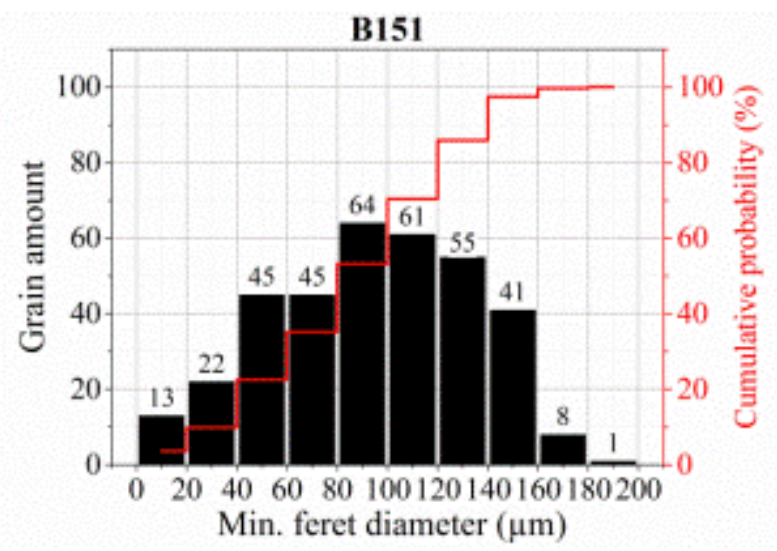

(c)

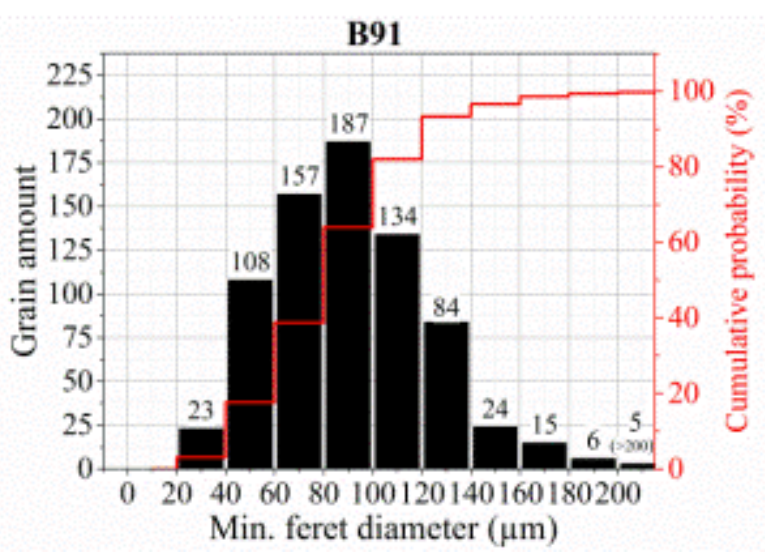

(d)

Figure 13. Feret diameters of B151 and B91: (a) $F_{\max }$ of B151, (b) $F_{\max }$ of B91, (c) $F_{\min }$ of B151, (d) $F_{\min }$ of B91

According to the quantity and dimension analysis, it is found that the total grain quantity and phase fraction of the B91 on the surface is approximately twice as that exhibited by the B151. 76.9\% (about 273 out of 355) grains of B151 and 85.7\% (about 637 out of 743) grains of B91 have a section area of less than $1.5 \times 10^{7} \mu^{2}$. $62 \%$ (about 220 out of 355) grains of B151 have perimeters of less than 433.5 $\mu \mathrm{m}$, i.e. the corresponding circle diameter is $138 \mu \mathrm{m}$ (mean grain size). 35\% (about 260 out of 743) grains of B91 have perimeters of less than $260.8 \mu \mathrm{m}$, i.e. the corresponding circle diameter is $83 \mu \mathrm{m}$ (mean grain size). In consideration of the machining quality of the workpiece, the honing stone B91 can achieve better smoothness than the honing stone B151, by reason of its higher grain density and small contact area of individual grains.

In accordance with the quantification results, grain properties of both honing stones have certain deviations from the specifications. This can be explained by the following reasons.

- The cross sections of the grains on the surface do not go exactly through the grain body center and the grain irregularly spatial distributions can also cause the difference to appear.

- Some defaults introduced in the polishing processes, such as grain eruption, particle cracking, etc., can also be responsible for the observed deviation.

- It can also result from the irregular grain profiles, such as elongated shape, which leads to expanded convex circularity in the segmentation, or from some large grains, which can be mixed in the manufacturing processes.

However, it is found that the grain dimensional properties of the honing stone B151 approximately conform to the specification, but the ones of the honing stone B91 seem to have large deviation from the theoretical ones. This may be rationalized considering that the grains of the honing stone B151 have lower density and larger size than the honing stone B91. Hence, it is more accurate to segment the grains of the former than those of the latter, using the same amount of acquired images with identical resolutions. In the case of the honing stone B91, it is necessary to use more morphological treatments to correct the defaults induced in the segmentation due to inadequate resolution, such as adhesion, impurities, etc. However, the morphological treatments can lead to some unexpected results. For example, the grain edge becomes smooth and the grain shape becomes more round after the operations such as erosion and dilation, which remove the blur asperities and smooth the grain borders. These observations can be proved by the results of convexity in Figure 11, which show that most of the grains of the honing stone B91 are approaching to be more round than those of the honing stone B151. Morphological treatments are more influential to the results of the honing stone B151, since the modification of the pixels has more impact on grain shape when the grains have smaller size. In addition, some common defaults induced in the polishing processes, e.g., grain eruption, particle cracking, etc. are also becoming more significant when the grains have smaller size. Reason for this is the fact that these default features may remain and be considered as grains by the software in the grain segmenta- 
tion. Thus, it is recommended to use higher resolution during the image acquisition for the honing stone with small grain size, in order to avoid excessive morphological treatments and obtain accurate results.

\subsection{Form parameters}

Typical grain forms of the honing stones are shown in Figure 14. With the calculation of grain shape factors, the statistics of grain shape are carried out in Figure 15. It is found that the mean value of the shape factor is 0.77 for the honing stone B151, and 0.88 for the honing stone B91, respectively. Most of the grains have a shape factor between 0.7 and 0.9 for the honing stone B151, which correspond with square and hexagon. On the other hand, shape factor is between 0.8 and 1.0 for the honing stone B91, which correspond with ellipse and circular, respectively. Thus, most of the grain sections on the surface have regular forms. The grains of the honing stone B91 exhibit more circular sections than those in the stone B151. Figure 16 shows the grain orientation on the surface of the honing stones. The grains are in general equally oriented in each direction.

Shape factor indicates the grain section shape that is related to the cutting edge in the abrasive process. The results demonstrate that $79.2 \%$ (about 281 out of 355) grains of B151 and $94.9 \%$ (about 705 out of 743) grains of B91 have a-shape factor between 0.68 and 1. This attests that most of the grains on the surface are polygons (rectangle-octagon-circle). The orientation analysis indicates that the grains are oriented almost evenly in each direction. In the case of fixed machining directions, the participation of the grain edges in the abrasive process can be considered approximately equal.

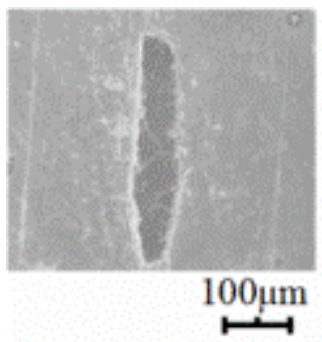

(a)

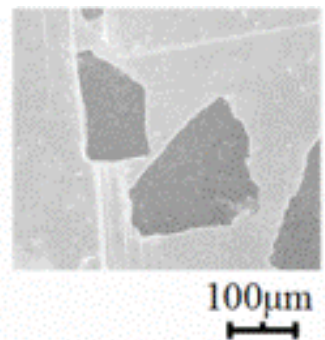

(b)

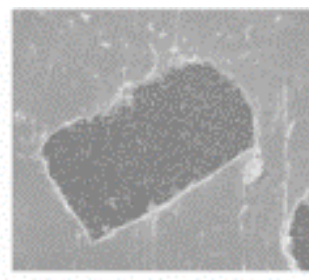

$\stackrel{100 \mu m}{\longmapsto}$

(c)

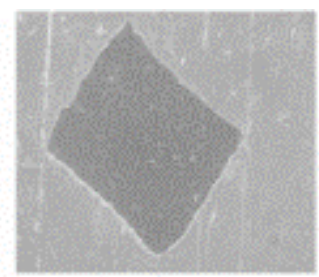

(d)

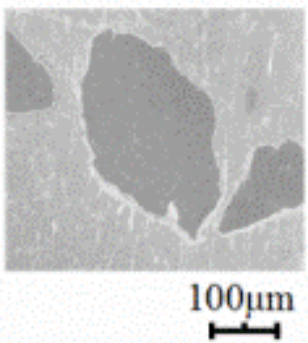

(e)

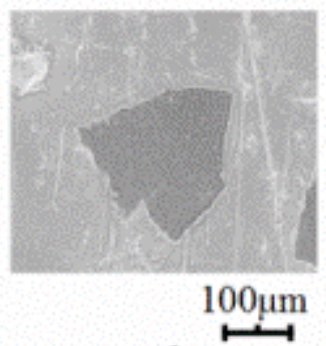

(f)

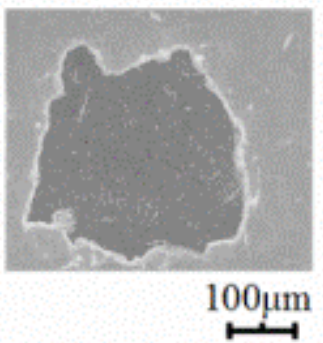

(g)

Figure 14. Typical grain shapes of CBN honing tools: (a) elongated, (b) triangle, (c) rectangle, (d) square, (e) ellipse, (f) pentagon, (g) circular 


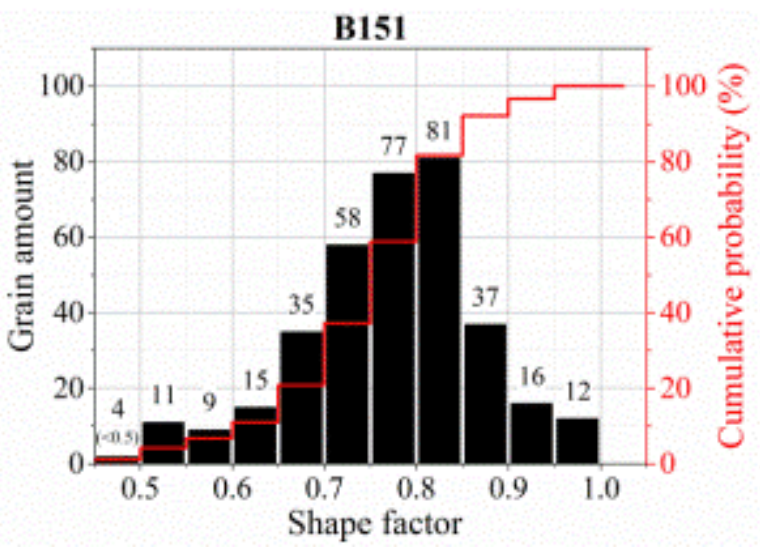

(a)

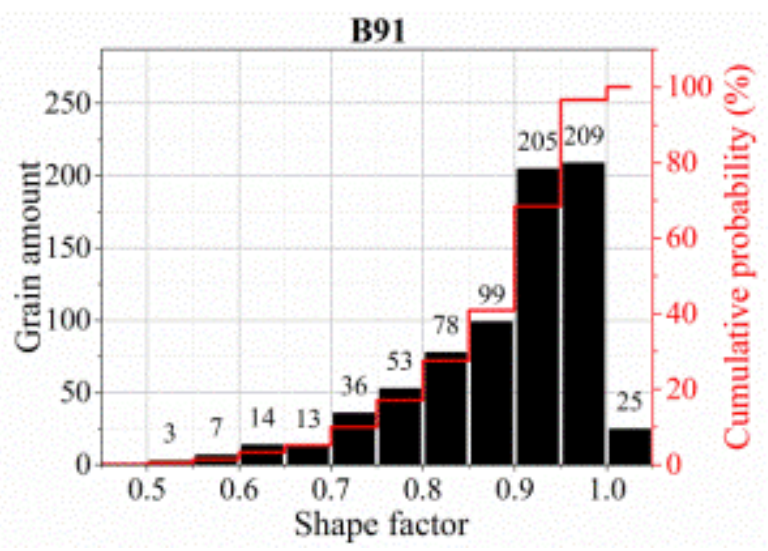

(b)

Figure 15. Shape factor histograms of B151 (a) and B91 (b)

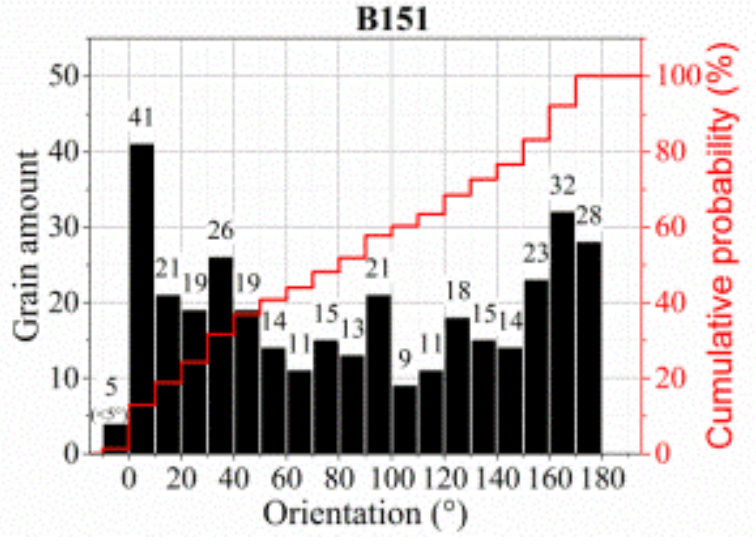

(a)

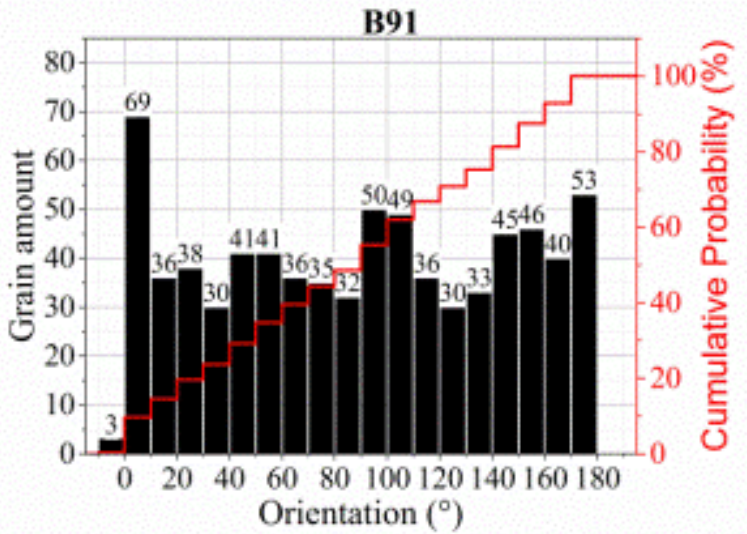

(b)

Figure 16. Grain orientation distribution of B151 (a) and B91 (b)

\subsection{Positional parameter}

It is found that the region homogeneities $h_{F}$ of the honing stones B151 and B91 are $82.80 \%$ and $88.08 \%$, respectively (Table 10). In terms of object number, both studied surfaces have close values, which means that the grains distribute similarly in the ten sections for each surface. However, the phase amounts in the ten sections of the studied surfaces have some certain differences, e.g., in the first five sections, the cumulative grain section occupies $43 \%$ of the total grain sections for the honing stone B151, and $46 \%$ for the honing stone B91, respectively (Figure 17). It indicates that grains of the honing stone B91 distribute more evenly in terms of phase amount.

The distribution analysis of the grains on the surface indicates that most of the grains of the honing stone B91, which has a higher phase fraction as well as higher grain density, have a more homogenous grain distribution than the honing stone B151. This could also testify that the machined surface by honing stone B91 can achieve better surface quality than the honing stone B151.

Table 10. Grain region homogeneities of B151 and B91

\begin{tabular}{llll}
\hline Honing stone & $\boldsymbol{H}_{\text {(objectnumber) }}$ & $\boldsymbol{H}_{\text {(Phase amount) }}$ & $\boldsymbol{h}_{\boldsymbol{R}}$ \\
\hline B151 & $92.10 \%$ & $89.90 \%$ & $82.80 \%$ \\
B91 & $93.7 \%$ & $94.0 \%$ & $88.08 \%$ \\
\hline
\end{tabular}




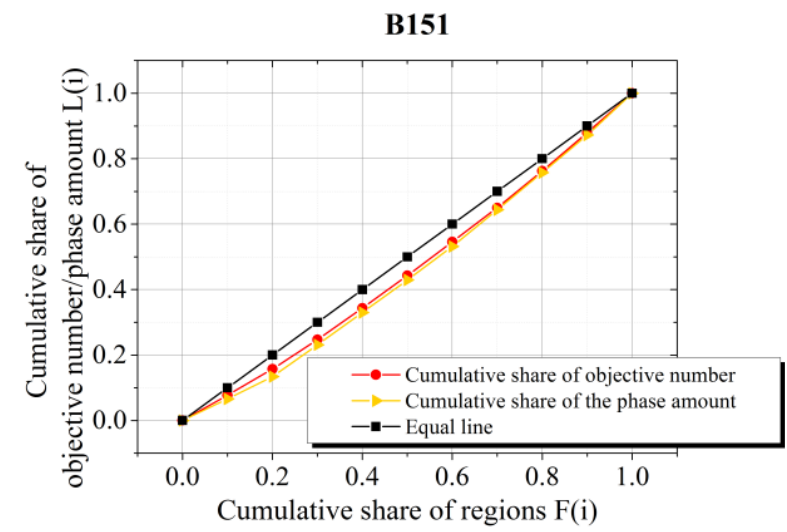

(a)

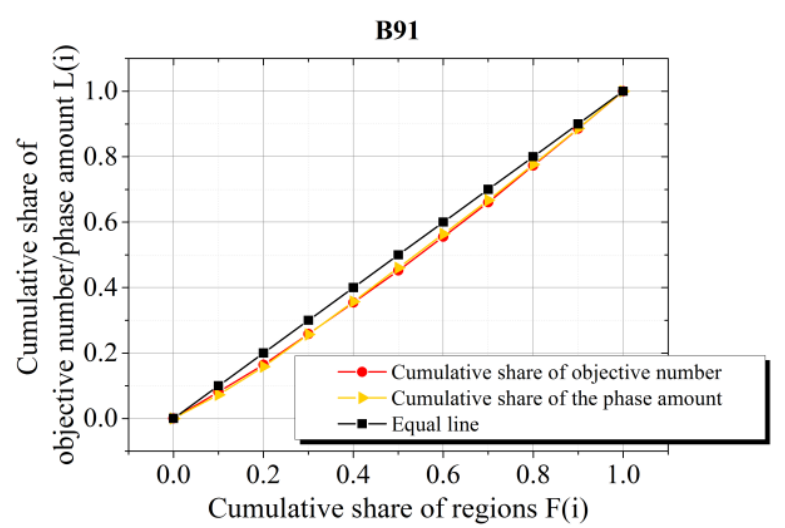

(b)

Figure 17. Lorenz curves of B151 (a) and B91 (b) region homogeneities

\section{Summary and concluding remarks}

The assessment method of the surface topography quantification by LSM allows for analyzing the geometrical characteristics of the abrasive grains on the tool cutting surface in two dimensions of the honing stones B151 and B91. The geometrical characteristics of single grains, in terms of quantity, dimension, form and position, have been evaluated and statistical investigation of all the grains has been conducted. In addition, the grain distributions on the surface are described by using the calculation of the region homogeneities.

To sum up, it has been proved that the surface topography quantification is an effective method to evaluate and obtain the important geometrical parameters of abrasive grains. The results are acquired based upon the systematic and statistical analysis of a great amount of grains. Therefore, the results are reliable and precise. However, some deviation from the specification of the honing stone B91 has been observed, and it is recommended to refine the scanning with higher resolution to obtain more precise results. Compared with the sampling inspection method to analyse single grains, this protocol allows for inspecting the tool surface area with large grain quantity in short time. The method is not only suitable for effective and quick characterization of existing abrasive tools, but also for the assessment of produced grain patterns on tool surfaces. However, the specimen dimension is limited by the LSM capacity; therefore, it is not able to characterize large abrasive tools. In addition, for the characterisation of small grains, longer time is required, since images with higher resolution are necessary.

\section{Acknowledgement}

The work is mainly supported by the DocMASE program and funded by the European Commission. Funding for this investigation was also partly supplied by the Spanish MINECO (Grant No.MAT MAT2015-70780-C4-3-P). The studied materials were supplied by KADIA Produktion GmbH + Co.. The authors would like to thank the aforementioned bodies as well as the EFRE Funds of the European Commission for support of activities within the AME-Lab project.

\subsection{References}

[1] S. N. Monteiro, A. L. D. Skury, M. G. de Azevedo, and G. S. Bobrovnitchii, "Cubic boron nitride competing with diamond as a superhard engineering material - an overview," J. Mater. Res. Technol., vol. 2, no. 1, pp. 68-74, 2013.

[2] R. H. Wentorf, "Synthesis of the Cubic Form of Boron Nitride," J. Chem. Phys., vol. 34, no. 3, p. 809, 1961.

[3] S. Saketi, S. Sveen, S. Gunnarsson, R. M'Saoubi, and M. Olsson, "Wear of a high CBN content PCBN cutting tool during hard milling of powder metallurgy cold work tool steels," Wear, vol. 332-333, pp. 752-761, 2015. 
[4] Y. Wang, K. Lei, Y. Ruan, and W. Dong, "Microstructure and wear resistance of CBN/Ni-Cr-Ti composites prepared by spark plasma sintering," Int. J. Refract. Met. Hard Mater., vol. 54, pp. 98-103, 2016.

[5] A. McKie, J. Winzer, I. Sigalas, M. Herrmann, L. Weiler, J. Rödel, and N. Can, "Mechanical properties of CBN-Al composite materials," Ceram. Int., vol. 37, no. 1, pp. 1-8, 2011.

[6] T. Sugihara and T. Enomoto, "High Speed Machining of Inconel 718 Focusing on Tool Surface Topography of CBN Tool," Procedia Manuf., vol. 1, pp. 675-682, 2015.

[7] G. Zhi, X. Li, W. Bi, J. Tang, and Y. Rong, "The measurement and analysis of micro bonding force for electroplated CBN grinding wheels based on response surface methodology," Eng. Fail. Anal., vol. 57, pp. 377388, 2015.

[8] Li, H. N., Axinte, D., Textured grinding wheels: A review, International Journal of Machine Tools and Manufacture, 2016, 109:8-35, DOI:10.1016/j.ijmachtools.2016.07.001.

[9] Burkhard, G., Rehsteiner, F., Schumacher, B., High Efficiency Abrasive Tool for Honing, CIRP Annals - Manufacturing Technology, 51/1:271-274, 2002, DOI:10.1016/S0007-8506(07)61515-7.

[10] Kirsch, B., Aurich, J. C., Influence of the macro-topography of grinding wheels on the cooling efficiency and the surface integrity, Procedia CIRP, 13:8-12, 2014, DOI:10.1016/j.procir.2014.04.002.

[11] Aurich, J. C., Herzenstiel, P., Sudermann, H., Magg, T., High-performance dry grinding using a grinding wheel with a defined grain pattern, CIRP Annals - Manufacturing Technology, 57/1:357-362, 2008, DOI:10.1016/j.cirp.2008.03.093.

[12] Ichida, Y., Sato, R., Kajino, H., Development of Ultrafine-Crystalline cBN Abrasive Grains for Innovative Grinding Technology, pp. 463-466, 2008,.

[13] Dahmen, T., Engstler, M., Pauly, C., Trampert, P., Jonge, N. de, et al., Feature Adaptive Sampling for Scanning Electron Microscopy, under review Nature: Scientific Reports, /April:1-11, 2016, DOI:10.1038/srep25350.

[14] Rossi, P., Engstler, M., Mücklich, F., Quantitative Classification and Assessment of Sr Modification in Hypoeutectic Al-Si and Al-Si-Mg Alloys, Practical Metallography, 52/10:571-589, 2015, DOI:10.3139/147.110361.

[15] T. A. Mahmoud, J. Tamaki, and J. W. Yan, "Three-Dimensional Shape Modeling of Diamond Abrasive Grains Measured by a Scanning Laser Microscope," Key Eng. Mater., vol. 238-239, pp. 131-136, 2003.

[16] Kaplonek, W., Nadolny, K., Laser methods based on an analysis of scattered light for automated, inprocess inspection of machined surfaces: A review, Optik, 126/20:2764-2770, 2015, DOI:10.1016/j.ijleo.2015.07.009.

[17] Xie, J., Wei, F., Zheng, J. H., Tamaki, J., Kubo, A., 3D laser investigation on micron-scale grain protrusion topography of truncated diamond grinding wheel for precision grinding performance, International Journal of Machine Tools and Manufacture, 51/5:411-419, 2011, DOI:10.1016/j.ijmachtools.2011.01.010.

[18] VDI 3394-1980: Aufbau und Anwendung von Schleifkörpern mit Diamant und kubisch kristallinem Bornitrid (CBN) für die Metallbearbeitung Hrsg.vom Verein Deutscher Ingenieure Ausg. Juni 1980

[19] H. K. Tönshoff, C. Arendt, and R. Ben Amor, "Cutting of Hardened Steel," CIRP Ann. Manuf. Technol., vol. 49, no. 2, pp. 547-566, 2000.

[20] FEPA-Standard, Bezugsquelle: Fachverband der Werkzeugindustrie, Elberfelderstr.77, BRD 5630Remscheid

[21] Flores Gerhard, Grundlagen und Anwendungen des Honens. Essen: Vulkan-Verl., P73, 1992

[22] F. Klocke and W. König, Fertigungsverfahren 2: Schleifen, Honen, Läppen. pp 58-60, 2005.

[23] a4i Micro/Quant Benutzerhandbuch, Aquinto AG, Berlin, P48, 2003 
[24] Malvern Instruments Ltd, “A basic guide to particle characterization," Inf. White Pap., pp. 1 - 26, 2012.

[25] E. Olson, "Particle Shape Factors and Their Use in Image Analysis - Part 10]: Theory," J. GXP Compliance, vol. 15, no. 3, pp. 85-96, 2011.

[26] L.R. Feret, La Grosseur des Grains des Matieres Pulverulentes, Assoc. Internat. pour l'Essai des Mat. Zurich 2D, P428, 1931.

[27] W. H. Walton, "Feret's Statistical Diameter as a Measure of Particle Size," Nature, vol. 162, pp. 329$330,1948$.

[28] E. E. Underwood, "Stereology, or the quantitative evaluation of microstructures," J. Microsc., vol. 89, no.2, November 1968, pp. 161-180, 1969.

[29] P.E. Danielson, “A new shape factor,” Comput. Graph. Image Process, vol. 7, no. 2, pp. 292-299, Apr. 1978.

[30] Henk G. Merkus, Particle Size Measurements:Fundamentals, Practice, Quality, Springer Particle Technology Series, Volume 17,P28-P34, 2009.

[31] F. Akbaripanah, F. Fereshteh-Saniee, R. Mahmudi, and H. K. Kim, "Microstructural homogeneity, texture, tensile and shear behavior of AM60 magnesium alloy produced by extrusion and equal channel angular pressing," Mater. Des., vol. 43, pp. 31-39, 2013.

[32] L. Ceriani and P. Verme, "The origins of the Gini index: Extracts from Variabilità e Mutabilità by Corrado Gini," J. Econ. Inequal., vol. 10, no. 3, pp. 421-443, 2012.

[33] P. Rossi, M. Engstler, and F. Mücklich. Homogeneity Quantification Method and its Application to Microstructure Assessment, Practical Metallography: Vol. 51, No. 3, pp. 180-199, 2014.

[34] J. L. Gastwirth, "The Estimation of the Lorenz Curve and Gini Index," Rev. Econ. Stat., vol. 54, no. 3, pp. 306-316, 1972.

[35] M. Novak and S. Deepak, "Comparing 3D Optical Microscopy Techniques for Metrology Applications," Bruker Nano Surfaces Div. Appl. Notes, 2013. 